\title{
A EXTENSÃO NA CONCEPČ̃O DOS DOCENTES DA ÁREA RURAL DA UFPEL: CONTRIBUIÇÕES DE UMA ANALISE $^{1}$
}

\author{
OUTREACH PROJECTS IN THE CONCEPTION OF \\ PROFESSORS FROM RURAL AREAS AT UFPEL: \\ CONTRIBUTIONS OF AN ANALYSIS
}

Darlan Pez Wociechoski* Nádia Velleda Caldas** Marcio Silva Rodrigues***

\begin{abstract}
Resumo: O objetivo deste estudo foi analisar as concepções de extensão dos professores da Universidade Federal de Pelotas (UFPel) ligados à área rural, tomando como apoio as categorias funcional (ou tradicional), processual e crítica, descritas por Silva (2001). Buscouse também discutir a necessidade de um reposicionamento epistemológico nas práticas universitárias para efetivação da concepção crítica. Assim, foi realizado um estudo qualitativo in loco que contou com coleta de dados por meio de entrevistas semiestruturadas com onze professores da UFPel, as quais foram submetidas à análise interpretativo-descritiva. Os resultados indicam uma prevalência da concepção processual de extensão na UFPel. Ao final, enaltecemos a necessidade de promoção de metodologias dialógico-participativas para efetivação do comprometimento das atividades de ensino e pesquisa com a realidade social comunitária, a fim de promover uma identidade universitária nacional.
\end{abstract}

Palavras chave: Concepção; Docente; Extensão universitária; Crítica; Epistemologia.

\begin{abstract}
The aim of this study was to analyze the conceptions about outreach projects of professors linked to the rural area of the Federal University of Pelotas (UFPel, Portuguese acronym) based on categories such as: functional (or traditional), procedural and critical as described by Silva (2001). Another aim was to discuss the need to adjust the epistemology in the university practices so that the critical conception is implemented. To this end, a qualitative study, which included data collection by means of semi-structured interviews with elevetn professors from the UFPel was carried out. The interviews were analyzed according to a descriptive-interpretative approach. The results indicate the prevalence of the procedural conception of outreach projects at the UFPel. The study also highlights the need of participative-dialectical methodologies for the implementation of teaching and research activities committed to the community social reality as well as the promotion of a national university identity.
\end{abstract}

Keywords: Conception; Professor; Outreach university projects; Criticism; Epistemology. 


\section{Introdução}

O debate sobre as concepções de extensão universitária está longe de um consenso, apresentandose, por vezes, como um assunto inacabado, mas recorrente no Brasil (SOUSA, 2001). Embora a teoria aflua "para uma concepção de extensão redimensionadora da pesquisa e do ensino vinculados às necessidades reais da sociedade" (MOROSINI, 2001, p. 33), há uma dificuldade no cotidiano universitário de colocá-la em prática. Tal problema decorre, em nosso entendimento, porque a condição para essa concepção ser posta em prática envolve um árduo reposicionamento epistemológico - como descreveremos na próxima seção.

Levando em consideração essa problemática, procuramos superar o debate estritamente teórico para avançar nessa discussão, tendo como objetivo a análise das concepções de extensão de docentes de uma universidade pública brasileira. Nesse sentido, tratouse de uma pesquisa in loco na Universidade Federal de Pelotas (UFPel) e com abordagem eminentemente qualitativa. Por meio da análise dos objetivos dos projetos de extensão vigentes para o ano de 2015, cadastrados no Sistema de Extensão Universitária da Pró-Reitoria de Extensão e Cultura da UFPel até 08 de março do mesmo ano, considerando a vinculação das suas ações para o meio rural ${ }^{2}$ e a disponibilidade dos seus coordenadores, foram selecionados 11 docentes para entrevista semiestruturada.

As entrevistas foram realizadas no ano de 2016 nos respectivos gabinetes dos docentes ${ }^{3}$. Os dados coletados foram submetidos à análise interpretativodescritiva, tomando como base, principalmente, as três concepções de extensão retiradas do trabalho de Silva (2001): funcional (ou tradicional), processual e crítica. Além disso, para auxiliar na análise e discussão dos dados, outros autores foram somados, como Freire (2014) e Cunha (2012).

Este trabalho está estruturado, além desta introdução, em outras três seções: a segunda reserva-se a apresentar e situar o referencial teórico; na terceira é exposta a análise e discussão dos dados; e, por fim, são apresentadas nossas considerações finais.

\section{Universidade e extensão}

Ao analisarmos a educação superior brasileira, reconhecemos alguns modelos institucionais de ensino atuantes no cotidiano universitário com seus princípios e estratégias de ação. A transmissão de conhecimentos do modelo franco-napoleônico, do professor "detentor do saber" e do aluno "tábula rasa", prevalece na maioria dos cursos de graduação. A associação do ensino à pesquisa, na ótica germânica-humboldtiana, é mais bem trabalhada na pós-graduação. É preciso atentar que, conforme apresentado no trabalho de Cunha (2012, p. 19), "em ambos os casos, o conhecimento é poder e está a serviço de ideologias e do domínio de grupos sobre outros grupos”.

O desafio apresenta-se exatamente em contrapor esses modelos estrangeiros de educação superior em favor do fortalecimento da identidade universitária brasileira. Entrando, em uma revolução epistemológica e repensando as relações da universidade pública, enquanto parte do Estado, com o restante da sociedade civil no processo de produção e reprodução de conhecimentos, o debate da extensão universitária mostra-se fundamental, pois "exige que a universidade [...] tenha responsabilidade com o desenvolvimento social equilibrado, produzindo saberes com e para a melhoria de vida de toda a população" (CUNHA, 2012, p. 21).

A inserção da extensão como função acadêmica
acena como uma nova epistemologia que estaria
valorizando os contextos de práticas como ponto
de partida do conhecimento cientifico. Derruba a
tese da neutralidade da ciência e assume a relação
entre os saberes de origens diversas como
legítimos e necessários. Reconhece a dimensão
política e cultural do conhecimento e de suas
formas de produção. (CUNHA, 2012, p. 21).

Atentamos que, para ocorrer essa verdadeira revolução epistemológica, não é possível continuar insistindo unicamente em lutas por espaço para a extensão universitária, tampouco retroceder em práticas assistencialistas ou 'culturalistas'. É necessário transcendê-las, em última análise. Importa colocar a extensão no mesmo sentido do ensino e da pesquisa (TAVARES, 2001; SILVA, 2001).

De modo semelhante, Demo (2001) e Botomé (2001) situam essa questão. No entendimento de Demo (2001) a extensão universitária aparece como má consciência da universidade, porque esboça um papel reparatório e porque não consegue trazer para o currículo o desafio social e a questão da cidadania. Por sua vez, Botomé (2001) percebe a extensão universitária na compensação de uma pesquisa alienada e um ensino alienante, que aparecem desconectados da realidade social. Num momento em que o ensino e a pesquisa aparecem acríticos, alheios às necessidades da sociedade, a extensão aparece como "redentora" do compromisso social da universidade. $\mathrm{Na}$ expressão do autor, a extensão acaba "camuflando mais do que comprometendo o trabalho da universidade com a sociedade" (BOTOMÉ, 2001, p. 162).

Boaventura de Sousa Santos (2010) corrobora a ideia de que a universidade precisa abraçar outras formas de democratização do conhecimento. Além do papel estratégico da própria extensão, ele defende a pesquisa-ação e a ecologia de saberes. O entendimento do autor parece estar correlacionado - com os devidos cuidados - à concepção de extensão de Botomé (2001) e Demo (2001), pois Santos (2010) defende a extensão universitária enquanto prestadora de serviços para toda a sociedade - desde as organizações populares até o setor privado - e percebe, ao mesmo tempo, a pesquisa-ação e a ecologia de saberes ${ }^{4}$ como "áreas de legitimação da universidade que transcendem a extensão uma vez que tanto actuam ao nível desta como ao nível da pesquisa e da formação" (SANTOS, 2010, p. 74). 
Cabe, em último lugar, a compreensão de que a defesa da extensão universitária no sentido exposto nos direciona a rever outras concepções que predominaram no contexto brasileiro. A crítica de Botomé (2001) resume esse histórico até meados do final do século passado, mas que, em nossa visão, ainda se estende até os dias atuais, em muitos espaços universitários brasileiros.

Em uma primeira etapa, a extensão aparece e se autodefine como "redentora" da pesquisa científica e do ensino superior. Pouco tempo depois, a extensão é reconhecida como uma "terceira" atividade das universidades: um terceiro "pé" que apoia a inserção social da universidade. Logo a seguir, de redentora e de terceiro "pé", a extensão universitária passa a ser "o caminho da redenção", sendo a "via de mão dupla": levando a universidade à sociedade e esta à universidade. Mesmo mantido o discurso oficial nessas metáforas e concepções, o processo de realização das atividades de extensão universitária prosseguiria. Os anos seguintes iriam encontrar a extensão universitária começando a ter o papel de "anúncio e propaganda" da universidade. Ela passava a ser uma "face" (fachada?) que administradores e governos queriam mostrar como "sendo a universidade". Com isso, a extensão passa a ser utilizada como aparência de compromisso social, camuflando mais do que comprometendo o trabalho da universidade com a sociedade. (BOTOMÉ, 2001, p. 162).

De modo mais teórico e conceitual, o trabalho de Silva (2001) elucida e sintetiza as concepções de extensão universitária no Brasil. Para a autora, conforme o quadro abaixo, três visões são perceptíveis de universidade-extensão, as quais se traduzem nos seguintes termos: tradicional (ou funcionalista), processual e crítica.

\begin{tabular}{|c|c|c|}
\hline Concepção tradicional & Concepção processual & Concepção crítica \\
\hline $\begin{array}{l}\text { A Universidade é vista como } \\
\text { um complemento do Estado, } \\
\text { desempenhando o papel de } \\
\text { mera executora das políticas } \\
\text { educacionais. A Extensão é } \\
\text { entendida como uma função } \\
\text { específica, autônoma, sendo } \\
\text { a desarticulação com o o } \\
\text { Ensino e a Pesquisa } \\
\text { praticada e considerada } \\
\text { natural. A Extensão } \\
\text { baseia-se no atendimento } \\
\text { das carências imediatas da } \\
\text { população, em uma } \\
\text { perspectiva apolitica e e } \\
\text { assistencialista (grifo da } \\
\text { autora). Há um discurso } \\
\text { inflamado que a coloca na } \\
\text { condição de representar a } \\
\text { saída para a Universidade, } \\
\text { no sentido de desenvolver o } \\
\text { vínculo com a sociedade, } \\
\text { mas contraditoriamente, na } \\
\text { prática, ela acaba } \\
\text { reduzindo-se a açôes } \\
\text { esporádicas, eventuais e } \\
\text { secundárias. }\end{array}$ & 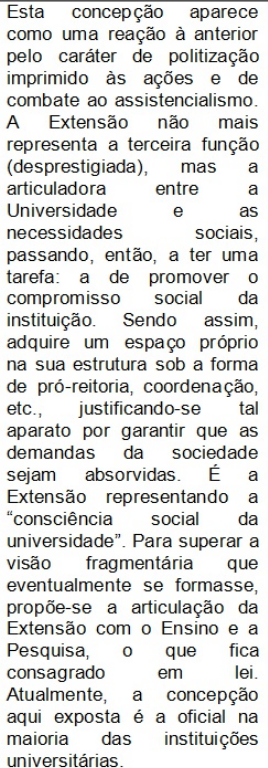 & $\begin{array}{l}\text { Esta tendência surge como uma } \\
\text { nova leitura de Extensão, que } \\
\text { se diferencia das anteriores. } \\
\text { Nela, a Extensão está } \\
\text { intrinsicamente ligada ao Ensino } \\
\text { e à Pesquisa, é sua essência, } \\
\text { sua característica básica, } \\
\text { apenas efetivando-se por meio } \\
\text { dessas funções. Portanto, } \\
\text { passa a ser entendida como } \\
\text { matéria de currículo. Não se } \\
\text { justifica, assim, sua } \\
\text { institucionalização, pois não se } \\
\text { concebe que esta tenha vida } \\
\text { própria, autonomia. Daí dizer-se } \\
\text { que "a extensão é duas, não é } \\
\text { três. Do raciocínio nós } \\
\text { eliminamos a extensão. Ela se } \\
\text { transforma em ensino e e } \\
\text { pesquisa" (AZAMBUJA, 1997, p, } \\
\text { 43). Transforma-se em um } \\
\text { conceito ocioso, porém exige } \\
\text { que o Ensino e a Pesquisa } \\
\text { sejam comprometidos com a } \\
\text { realidade, que o conhecimento } \\
\text { produzido e transmitido seja } \\
\text { inserido e contextualizado nesta } \\
\text { realidade. }\end{array}$ \\
\hline
\end{tabular}

Para tanto, assinalamos nosso alinhamento com a concepção crítica descrita por Silva (2001), como uma atividade "intrinsecamente ligada ao Ensino e à Pesquisa" e que, como outros autores defendem, deve carregar um novo posicionamento epistemológico na produção e democratização do conhecimento científico, que valorize os saberes populares e evidencie o papel político e social da ciência.

\section{Concepções de extensão na UFPel}

Antes de adentramos na descrição das concepções de extensão dos docentes, faz-se necessário trazermos o perfil preliminar do grupo pesquisado. Dentre os entrevistados, 10 professores possuem doutorado e 1 está em doutoramento; 6 entrevistados eram do sexo feminino e 5 do sexo masculino; 4 professores não tiveram experiência anterior em extensão universitária ou rural; 5 professores participaram de extensão universitária anteriormente ao ingresso no magistério superior. Conforme a Tabela abaixo, é possível estabelecer ainda as seguintes características dos sujeitos da pesquisa: a idade dos entrevistados variou entre $32 \mathrm{e}$ 66 anos, com uma média de 47 anos; o tempo de docência variou entre 3 e 41 anos, sendo a média 17 anos; 6 professores são da Faculdade de Agronomia Eliseu Maciel (FAEM); 2 professores da Faculdade de Veterinária (FV); 2 professores da Faculdade de Nutrição (FN); e 1 professor da Faculdade de Educação (FaE).

Tabela - Os sujeitos da pesquisa

\begin{tabular}{|l|c|c|c|c|}
\hline & $\begin{array}{c}\text { Idade } \\
\text { (anos) }\end{array}$ & Lotação & $\begin{array}{c}\text { Tempo de } \\
\text { docência } \\
\text { na UFPel } \\
\text { (anos) }\end{array}$ & $\begin{array}{c}\text { Experiência } \\
\text { anterior em } \\
\text { Extensão }\end{array}$ \\
\hline PROFESSOR A & 43 & FaE & 13 & Não \\
\hline PROFESSOR B & 51 & FAEM & 20 & $\begin{array}{c}\text { Sim (universitária } \\
\text { e rural) }\end{array}$ \\
\hline PROFESSOR C & 43 & FAEM & 3 & Sim (universitária) \\
\hline PROFESSOR D & 66 & FAEM & 40 & Sim (rural) \\
\hline PROFESSOR E & 35 & FV & 3 & Sim (universitária) \\
\hline PROFESSOR F & 58 & FN & 29 & Não \\
\hline PROFESSOR G & 40 & FV & 7 & Sim (universitária \\
e rural)
\end{tabular}

Fonte: Elaboração do autor.

O universo analítico da UFPel está em conformidade com a diversidade de visões de extensão universitária. As diferenças aparecem tanto nas visões quanto nas práticas dos próprios docentes. A descrição 
das concepções dos sujeitos da extensão é feita de forma gradual, tomando como princípio norteador as categorias construídas por Silva (2001), quais sejam: tradicional, processual e crítica.

A exposição dos dados se inicia com a descrição de um docente situado dentro de uma concepção tradicional de extensão universitária, que, conforme Silva (2001, p. 97), "baseia-se no atendimento das carências imediatas da população, em uma perspectiva apolítica e assistencialista". Nesse caso específico, consta-se uma visão apoiada na realização de cursos para pessoas de extrema pobreza. O mesmo professor não respondeu objetivamente sobre a sua concepção de extensão. No trecho a seguir, há a descrição dos objetivos do projeto que ele coordena:

\begin{abstract}
[...] melhoria da qualidade de vida dessas pessoas do campo onde - de agricultura familiar de extrema pobreza - onde eles poderiam ter uma noção de como viver melhor, com a mínima quantidade que eles recebem, que uma pequena quantidade de terra, [...] O nosso objetivo [...] é atender eles e deixar eles mais ou menos capacitados pra atender as necessidades deles, de melhorar a sua renda. Ou seja, arrumando emprego ou cuidando da sua propriedade [...], atendendo a produção de alimentos própria. (PROFESSOR F).
\end{abstract}

Os demais professores aparecem distribuídos e entremeados dentro de uma concepção processual e crítica. Não obstante, as próprias concepções de extensão dos professores apresentaram-se, por vezes, diferentes e contraditórias com as descrições das próprias práticas. É o caso do Professor K, que pode ser classificado na categoria processual e com imbricações na crítica. Percebe-se um viés crítico da extensão vinculando-a "à formação dos alunos e até mesmo dos professores", mas não chega a romper uma hierarquia de produção de saberes, na qual a universidade se apresenta como superior a outras formas de conhecimento:

\begin{abstract}
[...] a extensão somada com a pesquisa e com o ensino ela tem... ela casa muito bem. Não trabalhar somente extensão, não trabalhar somente pesquisa, não só ensino. Acho que as três trabalhando em conjunto elas têm um sentido interessante. Qual que é o papel da extensão? Acho que o papel da extensão é um pouco nessa questão que eu estou colocando, a questão da complementação da formação do aluno. Pensando para o aluno, acho que vem para complementar essa formação dele [...]. (PROFESSOR K).
\end{abstract}

Apesar de colocar a extensão intimamente ligada à formação dos alunos, numa perspectiva de aproximação com a realidade, o entrevistado ainda traz consigo a marca linear de construção do conhecimento em sua visão, que acaba atomizando a extensão em uma perspectiva processual. Ainda na visão do Professor K:

A extensão hoje ela tem um papel muitas vezes de tá inserindo esses alunos, inserindo esses bolsistas nesses ambientes, não vou dizer mais práticos, tem esse papel de estar inserindo nesses ambientes, nessa sociedade e tá fazendo depois, eles poderem estar fazendo depois um contraponto do que é apresentado na literatura.

A concepção processual de extensão revela, de fato, essa absorção parcial do compromisso social da universidade, porque não consegue promover um rompimento epistemológico, como defende Cunha (2012, p. 21), pois não "assume a relação entre os saberes de origens diversas como legítimos e necessários", tampouco "reconhece a dimensão política e cultural do conhecimento e de suas formas de produção". Permanece a influência do modo positivista de produção de conhecimento, que privilegia o saber teórico como ponto de partida, restando ao "ambiente" - como denominou o Professor $\mathrm{K}$ - o papel de "complementação e contraponto".

Essa percepção do Professor K confere com sua própria prática, pois é frequente, na descrição de sua atividade extensionista, a atitude de "levar informação de políticas públicas" à comunidade. Embora apareça na descrição das atividades promovidas pelos demais membros do projeto de extensão o engajamento em trabalhos que promovam o "empoderamento" dos participantes da comunidade, tudo indica ser mais um objeto discursivo do que uma prática efetiva. Apesar de assinalar o papel da extensão na formação dos alunos, na fala do entrevistado, não é percebido um planejamento pedagógico dos discentes, uma vez que eles aparecem como auxiliares (bolsistas) e não como protagonistas. A extensão descrita pelo professor K, se não fosse desarticulada da pesquisa, poderia ser considerada orientada a uma concepção funcional, que coloca a universidade como prolongamento assistencial do Estado.

Ainda sobre o papel da extensão na formação dos alunos, mas com trabalhos concretos nesse sentido, podemos agrupar outros três professores identificados dentro da visão processual, que descrevem suas práticas e suas concepções de extensão nos seguintes termos:

Então a ideia era essa, assim, "linkar" o profissional do campo com o professor ou o pesquisador e ao laboratório para ter um refinamento da informação - mais precisa - e trazer o aluno para participar de tudo isso. [...] então, claro, a preparação desses alunos. Isso é fundamental. É a peça chave do que a gente percebe que a ação ela tem que ter o envolvimento direto do aluno. Porque o intuito dela, além de ser extensão para comunidade, além dela ter pesquisa, ela tem que ter o ensino integrado, aos três... (PROFESSOR G).

Então, tem visitas, coleta de amostras, coleta de material, conversa com o produtor para adquirir essas informações básicas e iniciais, mas também de observação, do que a gente vê, por exemplo, no caso no processo de ordenha. Então o nosso foco é ali, e analisa no laboratório depois, discussão em grupo [com alunos da graduação], que aí é um projeto de ensino. [...] aí pode entrar vários artigos para discussão que estejam relacionados ao tema, enfim, que a gente trabalha no grupo. E aí depois o retorno disso para o produtor, retorno do laudo para o produtor. 
(PROFESSOR E).

[...] depois que eu ingressei aqui foi uma área que eu me inseri e comecei a detectar, assim, potencialidades regionais, comecei a conhecer Arranjo Produtivo, como eram os elos da cadeia produtiva e a identificar lacunas. Então eu disse: 'não', nós vamos tentar juntar esforços aí e com isso aproximar os alunos dos cursos das agrárias pra - os quais eu ofereço a disciplina - aproximar esses alunos da realidade. (PROFESSOR J).

A última descrição, dada pelo Professor J, foi feita no início da entrevista e trazia indícios de uma concepção crítica. No entanto, quando questionado objetivamente sobre sua concepção de extensão, o entrevistado assinalou aspectos que apontam para características de uma ótica processual, como de ligações do ensino, extensão e pesquisa, mas também de interdependência dessas atividades.

Eu procuro ver assim: nós não criamos um pacote, eu achar que assim, enfim... por eu estar realizando uma pesquisa ou eu ter um conhecimento ou um notório saber, eu vou lá impor... eu sei que eu crio um choque cultural muito grande com isso. E eu acho que falta assim um tratamento ou uma formação prévia do nosso extensionista. Porque um dia eu me torno docente, um dia eu me torno pesquisador, outro dia eu me torno, meio de paraquedas, um extensionista. [...]. Aí pra fazer extensão, acho muito válido, enfim, levar o aluno da sala de aula da graduação pra extensão. Eu pesquisar alguma coisa e me preocupar em levar até o campo pra quem precisa. Agora, aquele que consegue fazer bem as três coisas tá mentindo. (PROFESSOR J).

Ainda na descrição dos coordenadores de projetos que compartilham a concepção processual, deparamo-nos com a realidade do Professor C, que apresenta vinculações do ensino com a pesquisa, bem como do compromisso social da universidade. Nesse sentido, com base na entrevista, esse professor se alinha a características dos professores anteriores, uma vez que a pesquisa que ele coordena segue uma ótica aplicada, mas que não valoriza os conhecimentos populares, tendo a extensão como meio de validação dos dados (experimento e difusão), tal como pode ser percebido na descrição que ele tece das relações entre pesquisa e extensão:

\begin{abstract}
[...] agora mesmo a gente vai começar a pegar os resultados mesmo. Porque eu tenho outro projeto que é de pesquisa e... com esse de pesquisa é que a gente vai conseguir alimentar melhor esse de extensão. Então, eu tenho um projeto grande de pesquisa na região [...]. (PROFESSOR C).
\end{abstract}

Outra questão que se repete no discurso do Professor C, começando a formar um padrão com outros professores, é a influência da extensão rural na extensão universitária, carregada, em parte, por conta da formação inicial e dos trabalhos em conjunto com organizações extensionistas: "Assim, eu sempre gostei de extensão. Na graduação eu era do PET... eu já vivia fazendo estágio extra. Daí eu sempre fazia na Emater" (PROFESSOR C). Ademais, é possível perceber conhecimentos do campo de extensão rural quando o professor faz a diferenciação entre assistência técnica e extensão rural (embora, equivocadamente, confunda e inverta as definições):

Eu não sou da área de extensão em si. Até sabe até... que tem uma diferença da assistência técnica pra extensão, são coisas diferentes. Porque a assistência técnica tu tens uma continuidade, a extensão até num nível acadêmico tu acaba não conseguindo ter aquela continuidade às vezes que a assistência técnica da Emater deveria ter. Mas, eu acho que não faz sentido, [...], eu trabalho com pesquisa básica científica, mas o papel da universidade sem a extensão não tem sentido. Nossa função é na sociedade. É com a comunidade. Pra que a gente faz pesquisa? Ah, é... análises físicas e tal... mas pra que que é isso aí? Pra quem que é isso aí? Então é a forma da gente tentar, né, hã, não ficar nem tão só na parte teórica e levar isso para o produtor... o termo não é nem levar... é a troca né?... saber o que ele precisa, o que ele almeja, qual é a expectativa dele pra tentar resolver, é isso aí... (PROFESSOR C).

No trecho destacado, podemos notar uma questão específica da extensão rural: a influência da crítica de Paulo Freire ao extensionismo rural introduzido até meados do ano 1968, quando seu o livro Extensão ou Comunicação? foi publicado no Chile. Percebe-se que o discurso dessa obra está sendo parcialmente incorporado na concepção do professor $\mathrm{C}^{5}$.

Seguimos ainda com a descrição de entrevistados que trabalham na ótica processual e com tendências à concepção crítica, como o Professor H, que procura evidenciar a busca do processo de trocas de conhecimentos em meio a uma relação de convívio mais duradouro com a comunidade, mas que, na prática, não se efetiva. Ele destaca:

Eu acredito que o ideal [de extensão], não sei se ele existe, mas seria do tipo que nós pudéssemos fazer com que os nossos alunos eles vivenciassem essa realidade [...] e que nós aqui pudéssemos ir conviver, conversar com quem está lá, com o produtor e trocar conhecimentos, trocar saberes e desenvolver atividades juntos que fossem positivas e produtivas pra ambos. Então os alunos iam conhecer a realidade que hoje a grande maioria não conhece e o produtor ele ia ter a possibilidade de alguém que vai levar alguma coisa, alguma tecnologia, que vá conversar sobre algumas coisas, algumas dúvidas que ele tenha e os alunos pudessem trazer isso aqui pra dentro pra nós aqui discutirmos. E também trazer os produtores pra trazer as experiências, os alunos trazerem essas experiência pra enriquecer a formação profissional. O que a gente consegue fazer? E ir e fazer alguma atividade pontual. Porque, claro, isso especificamente na minha área que é uma área que aqui é muito pouco desenvolvida. Então provavelmente se você vá pegar outras áreas talvez seja mais fácil. (PROFESSOR H).

O que mantém o aludido professor na concepção processual é que, quando questionado sobre a ligação da extensão com o ensino, essas atividades aparecem sob a forma de participação de alunos da pósgraduação na realização de cursos para comunidade acadêmica e não acadêmica; quando se refere à ligação 
com a pesquisa, esta é identificada pelo levantamento de informações por meio de questionários dentro de projetos de extensão. Isso pode ser observado nos trechos em que comenta as ligações com a extensão:

Uma ligação direta não. Assim. Mas os meus
coorientados, por exemplo, eles estão no projeto
de extensão. Esse de orientação dos produtores.
Nós tínhamos dentro dos projetos de medicinais,
tem o horto... e daí tem o projeto de ensino, seria
o curso de plantas medicinais [...] esse projeto,
por exemplo, de extensão ele também tem um
caráter de pesquisa no sentido de uma pesquisa de
campo no levantamento de dados. [...] Então tem
coisas que chega uma hora que a gente não sabe
mais se é pesquisa ou extensão. É, nesse caso, tem
outros casos que tu não tens direito definido se é
projeto de ensino ou se é projeto de extensão,
então essas coisas se interligam. (PROFESSOR
H)

Trata-se, neste caso, de conhecimento produzido na academia para ser ensinado aos agricultores ou aos alunos de graduação. Não transparece nessa entrevista uma intencionalidade orgânica na valorização dos conhecimentos populares pelo referido professor, nem o papel sociopolítico da valorização desses conhecimentos. Já as imbricações entre pesquisa e extensão aparecem através de levantamentos de informações dos "participantes-alvo".

Com maior clareza, o cenário de transição entre a concepção processual e a crítica aparece, outrossim, no discurso do Professor A que, apesar de defender a extensão no sentido estrito, como cursos e oficinas, trabalha com um posicionamento político ativo da universidade em relação à sua comunidade, enaltecendo $o$ potencial emancipador dos conhecimentos gerados na academia. Também, é possível perceber o questionamento do mesmo professor sobre o acesso de grupos sociais aos cursos formais de graduação - um ponto importante que o interliga à concepção crítica. Além disso, a pesquisa gestada pelo professor aparece em consonância com a realidade:

Então eu acho que a extensão ela é algo assim que talvez tenha a ver com a minha trajetória também de pessoa, antes de eu entrar para universidade eu também tive uma militância política fora da instituição. $\mathrm{Eu}$ me construí direto com movimentos, então eu já fazia militância. [...] é a forma que ela [a universidade] tem de levar esse conhecimento, esse saber que está sendo produzido aqui, levar para comunidade. Isso tem que acontecer e a extensão tem que fazer isso. [... Já conhecia pessoas do movimento [dos Trabalhadores Rurais Sem Terra... mas na verdade eu fui procurada, o projeto ele começa assim. Aí eu fui lá e disse: 'não', nós vamos fazer, vamos ver o que é possível fazer, eu já trabalhava com artesanato, eu já tinha na época uma pesquisa, só que era pesquisa que eu fazia, mas era extensão também, né? Porque a gente fazia oficinas de artesanato com mulheres para discutir o feminismo, sabe? Então era um espaço que a gente criava usando o artesanato como uma ferramenta para discutir o trabalho feminino e a gente via $\mathrm{o}$ artesanato como trabalho e o feminismo faz essa discussão. [...] eles precisariam de certa forma de ... se ambientar mais com o próprio ambiente acadêmico. Eles mesmo poderem vir mais para cá... porque se é um movimento de mão dupla, não é só a gente ir lá cumprir só as demandas deles, mas eles de alguma maneira acessar espaço. A gente não pode esperar delas ou deles, pode ser o casal, a gente não pode pensar deles fazerem uma universidade também, né? Eles não podem ter o direito de fazer agronomia, de fazer engenharia agrícola, de fazer... bem, 'ó'! tem o curso de veterinária tem para os próprios assentados. Que também foi uma luta política na UFPel bem pesada, não é pouca coisa também ter uns cursos desses, não é fácil, 'empoderar' os grupos populares não é todo mundo que quer. (PROFESSOR A).

De forma semelhante, outro professor aparece em uma fase de transição entre a concepção processual e a crítica. Suas atividades de extensão representam uma tendência a uma concepção crítica, pois há atividades de ensino, extensão e pesquisa entrelaçadas, mas, ainda, não é possível, nesse caso, encontrar sólidos indícios que apontem para um rompimento epistemológico.

[...] Então nós temos um projeto/um programa que tem a felicidade de conseguir juntar, de fato, o ensino, a pesquisa e a extensão. Então ele não tá registrado como um projeto de pesquisa, tu poderias ter me questionado isso: por que não... $\mathrm{Na}$ verdade, nós optamos por registrar como projeto de extensão, porque ele tem um caráter muito mais de extensão que dos outros três componentes. [...] Eu acho que... a grande dificuldade que nós temos para fazer uma extensão como eu acredito que deveria ser. Pra mim a extensão exige uma convivência, uma frequência de encontros, porque é desta interação que tu obtém os resultados, tanto pra um lado quanto pro outro, porque sempre tem uma relação de troca. Pra nós é fundamental porque retroalimenta inclusive as atividades de ensino, as aulas, as imagens e o teu modo de ver como o campo... (PROFESSOR B).

Tornam-se mais aclaradas as distinções entre a concepção processual e a crítica quando adentramos especificamente nas entrevistas com os coordenadores enquadrados nessa última categoria. Embora, eles carreguem, seguramente, em menor proporção, algumas características da concepção processual, são dois professores que "confundem" as atividades de ensino, pesquisa e extensão, porque em seus discursos e em suas práticas as atividades extensionistas se dividem entre ensino e pesquisa. Além do mais, há uma real valorização dos sujeitos e de seus contextos e conhecimentos em pé de igualdade com os acadêmicos. Porém, conforme destacamos, existem ainda alguns pontos que os interligam com a ótica processual.

O primeiro professor, que destacamos dentro da concepção crítica, trabalha com metodologias de pesquisa participativas e percebe a pesquisa, o ensino e a extensão entremeados no processo de construção do conhecimento com a comunidade. Segundo suas próprias palavras,

[...] na verdade essas coisas todas se misturam. A pesquisa que é feita nas propriedades, o retorno do que vem pra aula, da aula volta pro campo, então, na verdade isso é uma... [...] Que hoje na realidade você vincula a sua pesquisa nesse 
contexto, não tem como ser diferente [...] tem pesquisa, experimentos dentro das propriedades [...] Se trabalha com agricultores, com e para agricultores. Essa é a nossa filosofia. [...]. Fundamentalmente [com] metodologias participativas [...] essa nossa prática, a práxis nossa de estar lá com a família, conversar, busca informação, vê como funciona, vê a dinâmica de funcionamento do agroecossistema, vê como é que funciona/como é que se organiza a família/o agricultor [...]. (PROFESSOR D).

Quando questionado objetivamente sobre sua visão de mundo a respeito da extensão universitária, sobressaiu diretamente a influência da extensão rural, em especial das ideias apregoadas por Paulo Freire, tal como anunciamos anteriormente. $\mathrm{O}$ que concebe uma apropriação de fato das proposições de Freire por esse professor, ao que nos parece, deve-se à incorporação de metodologias de pesquisa participativas, que exigem um pesquisador-extensionista, diferentemente do sistema brasileiro de extensão e de pesquisa agropecuária, que atualmente coloca em campos opostos essas duas atividades que deveriam estar imbricadas.

\begin{abstract}
A extensão é parecida... é. A extensão universitária é muito parecida com a extensão rural, eu acho que majoritariamente o pessoal estende coisas, ao invés de ir lá, se envolver, construir coletivamente, participar, ser responsável, ser cúmplice, não chegar lá e querendo invadir culturalmente uma propriedade [...] Nossos trabalhos com agricultores aqui ele pauta muito em as ideias de Paulo Freire, uma lógica de Edgar Morin, a gente enxerga essa relação nossa lá, uma relação de tolerância, com respeito, uma abertura, nunca deixando de lado o rigor cientifico da coisa, mas é a partir do construtivismo mesmo, você constrói a coisa, não adianta chegar lá com uma receitinha pronta, você tá fazendo igual ao que fazia... (PROFESSOR D).
\end{abstract}

Além da realização da extensão por meio da pesquisa, é necessário destacar a presença de estudantes nesse processo, com maior destaque aos da pós-graduação, o que demonstra o caráter de aprendizagem dessas atividades. Nessa mesma linha trabalha outro professor, que descreve a necessidade de um programa que englobe pesquisa, ensino e extensão, não separado essas atividades, como hoje ${ }^{6}$ ocorre.

Enfim, um programa onde tu possas ter uma descrição e demonstrar que tu trabalhas e ter basicamente na pesquisa e na extensão um instrumento de ensino. Esta é a ideia. [...] hoje a gente ainda analisa, interpreta e delibera sobre aprovação de projetos e de extensão, de ensino, de pesquisa e se a gente for ler muitas vezes não é nenhum, nem outro, nem outro. Então tá lá: projeto de extensão, curso de tal coisa. Eu não entendo como projeto de extensão, é um curso, se fez um curso, que que é um curso? É um curso. (PROFESSOR I).

O Professor I exemplifica sua concepção de extensão universitária e permite que percebamos a participação dos sujeitos de fora da universidade na identificação e construção dos problemas, bem como da incorporação de questões propostas pelos partícipes que interfere incisivamente no próprio ato extensionista, como é o caso de desse professor, que questiona a sobreposição de ações desenvolvidas pela universidade e por outra instituição.

Comunicação. Comunicação e Interação, com quem? Com quem a gente tem atividade, enfim. Eu tenho dificuldade, talvez, de participar de um projeto ou um trabalho que eu não tenho vivência, não tenho formação, enfim. Então eu entendo extensão como vivência, como comunicação/interação. [...] É só a gente ir, ouvir, trocar ideias. E uma problemática que eu vejo no nosso trabalho é que em geral a gente quer ir pra solucionar problemas e quer dar resposta logo e normalmente não é assim. Então eu acho que a grande, a grande maturidade que tem que ter na extensão é aprender a dizer "não sei hoje, vou procurar pra ajudar" e levar a resposta que pode ser: "não sei". Fiz isso, isso e isso, conversei, testei, testamos isso, isso e isso, e não deu. [...] a gente tava numa propriedade e eu acho que eu ouvi isso pela quinta vez já, quinta ou sexta vez: "por que vocês não tem, não comprem uma Kombi venham todo mundo junto?" até eu já usei isso em minhas manifestações e de novo uma senhora lá na propriedade diz que nós éramos o sexto grupo que vinha entre universidade e Embrapa e não sei quem que ia lá pra fazer as mesmas coisas, as mesmas perguntas e que já tinham feito 20 vezes e "antes mesmo dela ter feito cirurgia da perna" também tinham ido lá e feito as mesmas perguntas e ninguém resolveu nada. $\mathrm{O}$ que eu quero dizer com isto? É que sim, talvez a gente não faça extensão, a gente vai lá fazer questionários e uma tentativa de conhecer o que está acontecendo e achar que a gente tá com o problema pronto e quer levar soluções. Então eu diria assim, o pressuposto básico da extensão é, bom, primeiro é: ouvir, é ouvir e conhecer [...] Conhecer aquela realidade, bom, se é um problema, qual é a origem e como é que nós podemos solucionar. (PROFESSOR I).

Aqui está uma questão que distingue os professores que pertencem à concepção crítica daqueles que atuam com base na concepção processual $\mathrm{e}$ funcional: eles não admitem a coisificação dos sujeitos, pelo fato de que estes não são tratados como objetos. Conhecer a realidade na concepção crítica de extensão significa envolver o restante da sociedade, sempre que possível, na identificação e resolução dos problemas. Não se trata, porém, de esperar as mudanças unicamente do restante da sociedade ou de desvalorizar os conhecimentos acadêmicos em relação ao saber popular, mas a universidade e o restante da sociedade devem ser cúmplices, em pé de igualdade, na construção de um mundo menos desigual e mais justo.

Para concluir, há uma predominância da visão processual de extensão na UFPel, decorrente de uma marcante tendência do trabalho de extensão em si, ora valorizando o papel comunicacional da extensão (invariavelmente desconectado do ethos universitário), ora estendendo saberes acadêmicos de modo diretivo, mas articulados com ensino e pesquisa, por se dizer coloquialmente, "em uma corrida de bastão", próprio da influência da visão positivista de conhecimento. Por outro lado, das atividades mais próximas de uma concepção crítica da extensão, encontramos o exercício de um ensino e de uma pesquisa participativa e dialógica com a comunidade, as quais enaltecem a necessidade de um reposicionamento epistemológico. 


\section{Considerações finais}

A promoção de um modelo universitário autenticamente nacional, que, de fato, promova a indissociabilidade entre ensino, pesquisa e extensão, ocorrerá quando a extensão agir através do ensino e da pesquisa, escamoteando a perpetuação de modelos estrangeiros que não atendem as necessidades da realidade do Brasil, como são os casos dos modelos de ensino superior franco-napoleônico e humboldtiano. Isso porque a inserção da extensão crítica rompe com perpetuação do professor "detentor único dos saberes" transmitidos ao aluno "tábula rasa" do modelo franconapoleônico, ao colocar a possibilidade de aprendizagem em contextos múltiplos, como corroboram nossos dados. O modelo brasileiro também questiona o modelo germânico, uma vez, além de romper com a relação "professor ensina para o aluno" e colocar alunos e professores "para ciência", incorpora essa condição, mas, com a extensão crítica, ainda consegue superar a pretensão de neutralidade cientifica e enaltecer a participação do restante da sociedade na construção do conhecimento voltado para a transformação social.

Embora no recorte da realidade atual da UFPel seja apresentado um quadro evolutivo dinâmico e contraditório, possivelmente resultante das transições operadas no campo institucional e cultural, ressaltamos que há ainda muito a ser feito para aproximar a atuação da universidade à realidade regional, dentro de uma lógica emancipadora. Contudo, não se trata de uma meta inalcançável, pois, conforme exposto, já existem materializados nas práticas de alguns professores indícios que apontam para esse caminho. Essa tendência se apresenta na vivência continuada com a comunidade, na vinculação de alunos em suas atividades para apropriação direta na realização de pesquisas "com" e não somente "para" a comunidade.

\section{Referências}

CUNHA, M. I. A indissociabilidade do ensino coma pesquisa e a extensão como referente da qualidade na universidade brasileira: um discurso em tensão. In: (org.). Qualidade da graduação: a relação entre ensino, pesquisa e extensão e o desenvolvimento profíssional docente. Araraquara: Junqueira \& Marins, 2012, p. 17-38.

DEMO, P. Lugar da extensão. Construção conceitual da extensão universitária na América Latina. In: FARIA, D. S. (org.). Construção conceitual da Extensão Universitária na América Latina. Brasília: Universidade de Brasília, 2001, p. 141-158.

FREIRE, P. Extensão ou comunicação? São Paulo: Paz e Terra, 2006.

MOROSINI, M. C (org.). A Educação Superior em

Periódicos Nacionais (1968 -1995), 2001. Disponível em: $<$ http://inep.gov.br/documents/186968/484330/Educa\%C3\% $\mathrm{A} 7 \% \mathrm{C} 3 \% \mathrm{~A} 3 \mathrm{o}+$ superior+em + peri $\% \mathrm{C} 3 \% \mathrm{~B} 3$ dicos + nacionais +\%281968-1995\%29/2c9adc20-a650-4c74-ac98$68678 \mathrm{e} 134 \mathrm{dc} 1$ ? version=1.3>. Acesso em: 11 set. 2017.

SANTOS, B. S. A universidade no século XXI: para uma reforma democrática e emancipatória da universidade. São Paulo: Cortez, 2010.
SILVA, M. G. M. Extensão Universitária no sentido do ensino e da pesquisa. In: FARIA, D. S. (org.). Construção conceitual da extensão universitária na América Latina. Brasília: Universidade de Brasília, 2001, p. 91-105.

SOUSA, A. L. L. Concepção de extensão universitária: ainda precisamos falar sobre isso? In: FARIA, D. S. (org.). Construção conceitual da Extensão Universitária na América Latina. Brasília: Universidade de Brasília, 2001, p. $107-126$.

TAVARES, M. G. M. Os múltiplos conceitos de extensão. In: FARIA, D. S. (org.). Construção conceitual da Extensão Universitária na América Latina. Brasília: Universidade de Brasília, 2001, p. 73-84.

\begin{abstract}
Notas:
1 O presente artigo é resultado da dissertação de mestrado, intitulada "Concepções de extensão e desenvolvimento na Universidade Federal de Pelotas: uma análise a partir dos seus atores" e defendida em 2016 no Programa de Pós-Graduação em Desenvolvimento Territorial e Sistemas Agroindustriais da Universidade Federal de Pelotas.

${ }^{2}$ A pesquisa teve como balizador as vinculações ao meio rural dos projetos de extensão, tendo em vista que também foram analisadas as concepções de desenvolvimento (agrícola, rural sustentável, e territorial) dos docentes da UFPel.

3 A pesquisa não passou pela aprovação do Comitê de Ética porque a universidade somente exige esse procedimento em casos que envolvam experimentos com humanos ou animais. Porém, foram considerados os cuidados éticos, como o sigilo da identidade dos sujeitos da pesquisa, e também foram solicitadas as permissões através de termo de cessão para gravação e utilização das respectivas entrevistas na presente pesquisa.

4 Sobre pesquisa-ação e ecologia de saberes, vide: "A universidade no século XXI: para uma reforma democrática e emancipatória da universidade" (SANTOS, 2010).

5 Como poderá ser notado mais à frente, quando destacarmos professores com vinculações mais próximas a concepção crítica, percebemos o Professor D com influências explícitas da extensão rural e que incorpora, com maior completude, as proposições de Freire.

${ }^{6}$ A demanda do professor foi atendida no mesmo ano da entrevista pela universidade, que começou a criar a estrutura de programa de ensino, pesquisa e extensão.
\end{abstract}

